\title{
Filopodia Initiate Choices Made by Sensory Neuron Growth Cones at Laminin/Fibronectin Borders in vitro
}

\author{
Timothy M. Gomez and Paul C. Letourneau \\ The University of Minnesota, Department of Cell Biology and Neuroanatomy, Minneapolis, Minnesota 55455
}

\begin{abstract}
Localized expression of environmental cues is thought to provide directional information to migrating neuronal growth cones by enhancing or suppressing axon outgrowth over limited regions. To investigate how such a mechanism may function in vivo, we observed growth cones of embryonic chick dorsal root ganglion neurons at a substratum border between the extracellular matrix components laminin and fibronectin in vitro using time-lapse phase-contrast and interference reflection microscopy. We found that patterns of laminin and fibronectin could locally promote or suppress the direction of growth cone migration. While migrating on either laminin or fibronectin, at least $79 \%$ of growth cones changed their rate and/or direction of outgrowth upon contact with the alternative substratum, in a manner suggesting that growth cones were selecting one substratum over the other. Complex changes in growth cone behavior were initiated by filopodial contact with the alternate substratum, suggesting that filopodia were providing intracellular signals to the growth cone. Using interference reflection microscopy, we have found that selection of a substratum is independent of the degree of close contact to the substratum. We conclude that spatially localized ECM components can direct axon outgrowth by mechanisms based on intracellular signaling through growth cone filopodia.
\end{abstract}

[Key words: laminin, fibronectin, filopodia, growth cone, interference reflection microscopy, guidance]

The local environment of the neuronal growth cone is critical for directing neurite outgrowth. Extracellular matrix (ECM) glycoproteins (Sanes, 1989; Letourneau et al., 1992), membraneassociated glycoproteins (Rutishauser et al., 1983; Chang et al., 1987; Lagenaur and Lemmon, 1987; Caroni and Schwab, 1988; Matsunaga et al., 1988), soluble factors (Gundersen and Barrett, 1979; Lumsden and Davies, 1986; Placzek et al., 1990; O'Leary et al., 1991), and proteoglycans (Carbonetto et al., 1983; Tosney and Landmesser, 1985a; Stern and Keynes, 1987; Snow et al., 1990a; Tosney and Oakley, 1990; Cole and McCabe, 1991) have been shown to affect growth cone migration either positively or negatively and are likely to function in combination in vivo.

\footnotetext{
Received Dec. 31, 1993; revised Mar. 18, 1994; accepted Mar. 29, 1994.

We thank Drs. Diane Snow and Maureen Condic for their insight during experimentation, and for critical comments on the manuscript. Portions of this work were presented in abstract form at the 1991 and 1992 annual meetings of the Society for Neuroscience. This research was supported by National Institutes of Health Predoctoral Training Grants EY07133 (T.M.G.) and HD19950 (T.M.G. and P.C.L.).

Correspondence should be addressed to Timothy $M$. Gomez, University of Minnesota, Department of Cell Biology and Neuroanatomy, 321 Church Street, SE, 4-135 Jackson Hall, Minneapolis, MN 55455.

Copyright (C) 1994 Society for Neuroscience $0270-6474 / 94 / 145959-14 \$ 05.00 / 0$
}

One mechanism proposed to guide growth cones in vivo is the restricted or graded expression of growth-influencing molecules that may produce pathways of preferred migration. Consistent with this proposal is the immunohistochemical localization of both growth-promoting and growth-inhibiting macromolecules along many neuronal migratory routes (Palm and Furcht, 1983; Rogers et al., 1986; Riggott and Moody, 1987; Harris, 1989; Snow et al., 1990b). Further evidence for local regulation of growth cone behavior along neuronal pathways is the presence of "decision points" where growth cones make stereotyped choices among several alternative routes (Tosney and Landmesser, 1985b; Caudy and Bentley, 1986; Bovolenta and Mason, 1987; Sretavan and Reichardt, 1993). At these decision regions, changes in direction of outgrowth are often accompanied by changes in growth cone morphology and/or rate of migration. The presence of pathways for neurite outgrowth is clearly demonstrated in the developing grasshopper limb and CNS, where identified growth cones display a strong preference for migration along certain neuronal and non-neuronal surfaces (Raper et al., 1983; Caudy and Bentley, 1986; Kolodkin et al., 1992). In further support of a role for local regulation of pathway sclection, many tissue culture studies have shown that growth cones can respond in specific ways to local variations in their environment (Harrison, 1914; Letourneau, 1975; Bonhoeffer and Huf, 1982; Gundersen, 1987; Snow and Letourneau, 1992).

Several models have been presented to explain growth cone steering both in vivo and at a substratum border in vitro. One model proposes that differential adhesion of filopodia may control the direction of neurite outgrowth (Letourneau, 1981; Bray, 1982). In this model, filopodia adhere to the substratum and exert tension, pulling the growth cone toward an area of highest adhesivity. Other models propose that the filopodia are a scaffold to support veil extension, and subsequent asymmetric regression (Burmeister and Goldberg, 1988) or production (Goldberg and Burmeister, 1986), of new areas of growth cone control in the direction of neurite outgrowth. Alternatively, studies of growth cone guidance of pioneer neurons in grasshopper embryos have shown steering is mediated by the dilation of a single filopodium in contact with a guidepost cell (O'Connor et al., 1990 ), in a process dependent on the accumulation of actin filaments (O'Connor and Bentley, 1993) and selective invasion of microtubules (Sabry et al., 1991).

Consistent with each model is the initial exploration of the environment by filopodia. Recent reports indicate that these exploratory filopodia, which greatly enhance the sampling area of a growth cone, are not only adhesive structures, but may function as a sensory effector system by expressing second messenger-linked cell surface receptors (Davenport et al., 1993; O'Connor and Bentley, 1993). In this model, filopodial contact 
with environmental cues generates receptor-based second messenger cascades, which ultimately regulate cytoskeletal dynamics and direct neurite outgrowth. Many growth-promoting molecules have recently been shown to alter second messenger systems (Bixby, 1989; Schuch et al., 1989; Doherty et al., 1991, 1993; Davenport and Kater, 1992).

The glycoproteins laminin (LM) and fibronectin (FN) are permissive substrata for the development of the peripheral nervous system, and the differential distribution of these two molecules in the periphery indicates possible roles in axon guidance (Rogers et al., 1986; Westerfield, 1987). Each of these molecules has multiple domains involved in cell attachment and/or neurite promotion (Reichardt and Tomaselli, 1991; Letourneau et al., 1992). Numerous putative receptors for both LM and FN cell binding domains have been described, the most common of which are members of the $\beta 1$ family of integrins (reviewed in Buck and Horwitz, 1987; Hynes, 1992). LM and FN possess multiple binding sites for distinct integrins (Reichardt and Tomaselli, 1991). Motor neuron growth cones, which grow well on LM, are unable to extend on FN (Rogers et al., 1983) and this inability may be one factor controlling guidance to their peripheral targets (Westerfield, 1987). Sensory neuron growth cones, on the other hand, extend neurites on both LM and FN and therefore may respond differently than motor axons to pathways consisting of a patterned distribution of these two molecules.

In this report, we examine growth cones of chick dorsal root ganglion (DRG) neurons at a border between LM and FN, using both phase-contrast and interference reflection microscopy (IRM). The purpose of this study is to assess the behavior of growth cones at the point of initial contact with a new substratum, when the interactions of receptors and associated intracellular systems are changing. We examine the kinetics of neurite outgrowth, growth cone morphology, and directional changes in neurite outgrowth at a border between LM and FN. In addition, the role of filopodia in initiating changes in growth cone behavior is analyzed. IRM is used to address the role of close substratum contact in the behavioral responses seen at the LM/ FN border.

\section{Materials and Methods}

Patterned substrata preparation. Acid-washed glass coverslips were mounted over $22 \mathrm{~mm}$ holes drilled into the bottom of $35 \mathrm{~mm}$ tissue culture dishes. Each dish was UV sterilized for 1-2 hr. Patterns consisting of alternating stripes of LM and FN were prepared in the following manner. Strips of silicone $2 \mathrm{~mm} \times 20 \mathrm{~mm}$ were cut from a 2-mm-thick sheet of silicone elastomer (Dow Corning 93-500 Space grade encapsulant, Dow Corning Corp., Midland, MI), sterilized in $70 \%$ ethanol, and placed onto a glass coverslip, creating a tight seal. EHS tumor LM (generous gift of Sally Palm, University of Minnesota) (Palm and Furcht, 1983) and FN, isolated from human plasma (generous gift of Jim McCarthy, University of Minnesota) (McCarthy et al., 1986), were diluted in PBS ( $\mathrm{pH} 7.1$ ) to a concentration of $10-50 \mu \mathrm{g} / \mathrm{ml}$. To locate the border between substratum proteins, $2.5-5 \%$ of the appropriate fluorochrome-conjugated form of LM or FN was added (rhodamine-LM or fluorescein-FN) to one or both solutions (conjugated by method of Harlow and Lane, 1988). Two hundred and fifty microliters of either LM or FN solution were applied to the exposed spaces of the coverslips around the silicone strips and incubated for $2-3 \mathrm{hr}$ at room temperature, then suctioned off, and the coverslips washed three times with PBS. To saturate any remaining protein binding sites, the coverslips were blocked with $10 \mathrm{mg} / \mathrm{ml}$ hemoglobin (Hgb) (Sigma Chemical Co., St. Louis, MO) in PBS for $2-3 \mathrm{hr}$ at room temperature. The Hgb was suctioned off, and the coverslips were again washed extensively with PBS prior to the removal of the silicone strips. Without allowing the plate to dry, $500 \mu 1$ of the alternate protein solution was applied to the entire coverslip and incubated for at least $6 \mathrm{hr}$ at room temperature. For some experiments the entire coverslip was subsequently blocked with $10 \mathrm{mg} / \mathrm{ml} \mathrm{Hgb}$. In most experiments, the first protein solution was used at $50 \mu \mathrm{g} / \mathrm{ml}$ and the second protein solution at $10 \mu \mathrm{g} / \mathrm{ml}$. The order that LM and FN were applied to the coverslip was interchanged regularly. For control studies, LM/LM and FN/FN patterns were produced in the same manner as described above, except equal concentrations of protein were used in the first and second coatings.

Characterization of the patterned substrata. The integrity of the LM/ FN patterns was tested both immunofluorescently and radiographically (immunofluorescent labeling produced a more intense staining of LM and FN than did the fluorochrome-conjugated forms of LM and FN, allowing us to better visualize the patterns). For immunofluorescence, patterned substrata were fixed for 20 min with $4 \%$ paraformaldehyde/

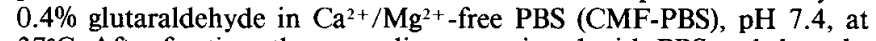
$37^{\circ} \mathrm{C}$. After fixation, the coverslips were rinsed with PBS and the substratum patterns were immunofluorescently labeled by the following protocol. First, the patterns were blocked with $10 \%$ normal goat serum (NGS; GIBCO Laboratories, Grand Island, NY) in PBS for $30 \mathrm{~min}$. The blocking solution was subsequently removed, and the following polyclonal primary antibodies were applied for $60 \mathrm{~min}$ : rat anti-LM, 1:100, and rabbit anti-FN, 1:100 (gift of Dr. Sally Palm, University of Minnesota) in $10 \%$ NGS. The coverslips were washed three times with PBS followed by a second $30 \mathrm{~min}, 10 \%$ NGS block. Coverslips were then incubated with 1:100 dilutions of rhodamine-conjugated goat antirat and fluorescein-conjugated goat anti-rabbit secondary antibodies (Cappel Laboratories, West Chester, PA) in 10\% NGS for $60 \mathrm{~min}$. The coverslips were washed a final time with PBS and mounted over second coverslips, using a carbonate-buffered glycerol medium containing a reducing agent ( $p$-phenylenediamine; Sigma Chemical Co.) to retard photobleaching.

The amount of LM and FN that binds to both blocked and unblocked glass coverslips was determined radiographically using ${ }^{3} \mathrm{H}$-conjugated forms of LM and FN, prepared in our laboratory according to the methods of Jentoft (Jentoft and Dearborn, 1979) and Herbst (Herbst et al., 1988). The amount of ${ }^{3} \mathrm{H}-\mathrm{LM}$ and ${ }^{3} \mathrm{H}-\mathrm{FN}$ binding to $12 \mathrm{~mm}$ round coverslips was quantitated at each step in the substratum patterning protocol described above. Therefore, we measured the amount of ${ }^{3} \mathrm{H}-$ $\mathrm{LM}$ and ${ }^{3} \mathrm{H}-\mathrm{FN}$ binding to clean glass, glass saturated with $\mathrm{LM}$ or FN, and glass subsequently blocked with $10 \mathrm{mg} / \mathrm{ml} \mathrm{Hgb}$.

Cell culture. Dorsal root ganglia (DRG) of the lumbar-sacral enlargement were dissected from embryonic day 8-11 white Leghorn chicken embryos and dissociated with $0.25 \%$ crude trypsin in CMF-PBS 7.89 , as described previously (Ludueña, 1973). Dissociated cells were suspended in serum-free medium consisting of $10 \mathrm{~mm}$ HEPES-buffered F14 medium (GIBCO Laboratories, Grand Island, NY) supplemented with $2 \mathrm{~mm}$ L-glutamate, $5 \mathrm{ng} / \mathrm{ml}$ sodium selenite, $5 \mathrm{ng} / \mathrm{ml}$ sodium pyruvate, $5 \mathrm{~mm}$ phosphocreatine, $20 \mathrm{~nm}$ progesterone, $5 \mu \mathrm{g} / \mathrm{ml}$ insulin, $100 \mu \mathrm{g} / \mathrm{ml}$ transferrin (all from Sigma Chemical Co., St. Louis, MO), and $15-50 \mathrm{ng} / \mathrm{ml} 2.5 \mathrm{~S}$ nerve growth factor (R\&D systems, Minneapolis, MN). An antibiotic/antimycotic solution (Sigma Chemical Co., St. Louis, $\mathrm{MO}$ ) was also added. Approximately $1.2-1.5 \times 10^{4}$ cells were seeded onto each patterned coverslip in $1.0 \mathrm{ml}$ of growth medium and incubated in a humidified air chamber at $40^{\circ} \mathrm{C}$ for at least $6 \mathrm{hr}$.

Videomicroscopy. Following incubation, a culture dish was placed on an inverted microscope (IM-35, Carl Zeiss, Inc., Thornwood, NY; or Diaphot, Nikon Inc., Garden City, NY) under an air curtain incubator (ASI 400, Carl Zeiss, Inc.), keeping the medium at a constant $40^{\circ} \mathrm{C}$. Growth cones were monitored by either phase-contrast optics, using a Newvicon video camera (NC-65, Dage-MTI, Inc., Michigan City, IN), or interference reflection microscopy (IRM), using an SIT camera (SIT66, Dage-MTI, Inc.). IRM was done on the IM-35 microscope using a $50 \mathrm{~W}$ HBO epiilluminator, $546 \pm \mathrm{nm}$ precision filler, Zeiss $\mathrm{H}-\mathrm{D}$ reflector, pre- and postobjective polarizers, 2 FL housing, and a Zeiss $63 \times$ antiflex objective. To prevent UV photodamage, growth cones were exposed intermittingly to light using a shutter (Uniblitz DI22, Vincent Associates, Rochester, NY). Immunofluorescence microscopy was performed on the Diaphot microscope using a Zeiss $100 \times$ Neofluor objective and a Paultek ICCD camera (Paultek Imaging, Nevada City, CA). Image enhancement and morphometric measurements were made using IMAGE 1 software (Universal Imaging, Inc., West Chester, PA) run on a 486/ 33 computer system (Gateway 2000, North Sioux City, SD). Images viewed with a video monitor (Trinitron, Sony Corp. of America, New York, NY) were recorded every $30 \mathrm{sec}$ with an optical disc recorder (TQ-2026F, Panasonic Industrial Comp., Secaucus, NJ). 

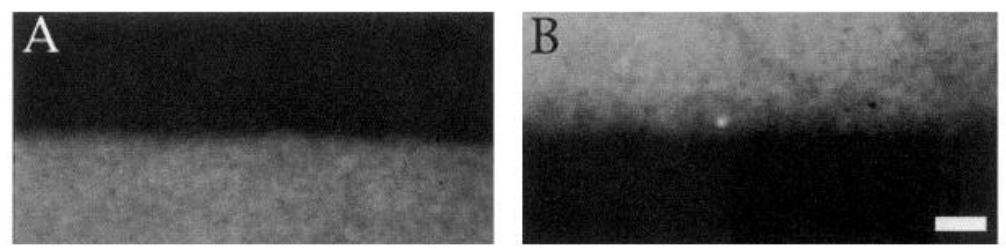

Figure 1. An LM/FN pattern that was immunofluorescently labeled for both LM (TRITC; $A$ ) and FN (FITC; $B$ ). LM and FN staining are both adjacent and nonoverlapping.

Quantitative analysis. Growth cones were scored for (1) crossing or turning at the border between LM and FN, (2) angle of neuritic approach, and (3) rate of growth cone migration, according to the following set of criteria: (1) a growth cone must have been observed from a position at least $20 \mu \mathrm{m}$ away from the border and followed for sufficient time to assess its behavior after contact with the border (typically growth cones were observed until they reached a point at least $20 \mu \mathrm{m}$ across the border, or until they became aligned parallel to the border); (2) growth cones must not have contacted any interfering cells within $20 \mu \mathrm{m}$ on either side of the border during the entire process of crossing or turning; (3) the angle a neurite makes with respect to the border was measured from the tip of the growth cone to a point $20 \mu \mathrm{m}$ down the neuritic shaft; (4) for growth cones that undergo an obvious behavioral change upon contact with the alternative substratum, the rate and angle of approach were measured prior to the beginning and after the completion of the change in behavior; (5) for those growth cones that did not undergo any obvious change in behavior, the rate and angle of approach were measured before and after the growth cone had migrated within $10 \mu \mathrm{m}$ of the border; and (6) when a branch occurred that was greater than $20 \mu \mathrm{m}$ from the border, each separate neurite was measured using the above criteria.

The average pixel intensity of the digitized IRM images was quantitated using IMAGE 1 software. The periphery of a growth cone (filopodia not included) was traced by hand to the proximal point where the growth cone consolidated into neurite.

\section{Results}

Prior to behavioral analysis, we examined the $\mathrm{LM} / \mathrm{FN}$ patterns in two ways. First, by double immunofluorescent labeling of the substrata, we found the LM and FN stripes to be both adjacent and nonoverlapping (Fig. 1). Second, using tritiated forms of $\mathrm{LM}$ and $\mathrm{FN}$, we detected $<10 \%$ binding of the overlay protein onto a substratum that had been previously saturated with LM or FN and subsequently blocked with $10 \mathrm{mg} / \mathrm{ml} \mathrm{Hgb} \mathrm{(Table} \mathrm{1).}$ These results demonstrate that we are able to generate patterned substrata suitable for testing a growth cone's response to a border between different growth-promoting molecules.

We analyzed growth cone behaviors at an LM/FN border between 6 and $36 \mathrm{hr}$ in culture, using high- and low-magnification phase-contrast microscopy as well as IRM. We identified the border between LM and FN by preparing patterned substrata with solutions that contained 5\% fluorescent conjugates of LM and/or FN. For high-magnification studies, growth cones located between 20 and $40 \mu \mathrm{m}$ from a border and oriented nearly perpendicular to it were recorded prior to, during, and after contact with the alternative substratum. When using low-magnification optics, a field containing neurons on both sides of the substratum border was recorded for up to $24 \mathrm{hr}$. We analyzed growth cones migrating toward FN while elongating on LM ("LM-to-FN growth cones"), as well as growth cones migrating toward LM while elongating on FN ("FN-to-LM growth cones").

Our data comprise observations of over 100 growth cones at an LM/FN border. Nearly all growth cones at a border between LM and FN exhibited behavioral changes upon contact with the new substratum. At the LM/FN border, growth cones exhibited changes in direction and rate of outgrowth, shape, filopodial turnover, and axonal branching. Changes in rate and direction of outgrowth were the most consistent, and were therefore quantified (below). As a control for any physical effects of a border, growth cone behaviors at an LM/FN border were compared to responses seen at borders between LM and LM, or FN and FN (Fig. $2 A, B$ ). Importantly, growth cone behaviors were not influenced by the order that the proteins were applied to the coverslip (see Materials and Methods).

\section{Change in direction and rate of migration are correlated at an $L M / F N$ border}

LM-to-FN growth cones. Sixty-two percent of the LM-to-FN growth cones $(n=74)$ crossed onto $\mathrm{FN}, 27 \%$ turned to remain associated with $\mathrm{LN}$, and $11 \%$ stopped at the border with FN for the duration of the observation period (average observation time at border, $4 \mathrm{hr}$ ). For comparison, $97 \%$ of the LM-to-LM growth cones crossed the border $(n=30)$. Directional and elongation rate changes for 63 of the 74 growth cones observed are summarized in Figure $2 C$. Seventy-eight percent of LM-to-FN growth cones underwent significant behavioral changes upon contact with FN, defined as a greater than $50 \%$ increase or decrease in rate of migration and/or a greater than $20^{\circ}$ change in direction of outgrowth. Only $12 \%$ of the LM-to-LM growth cones underwent changes in behavior by the same criteria $(n=$ 26).

The changes in direction and rate of migration exhibited by LM-to-FN growth cones were closely correlated, as indicated

Table 1. Binding of ${ }^{3} \mathrm{H}-\mathrm{FN}$ and ${ }^{3} \mathrm{H}-\mathrm{LM}$ is inhibited by prior treatment of substratum with $\mathrm{LM}$ or FN and $\mathbf{H g b}$

\begin{tabular}{llllll} 
& {$[\mathrm{LM}](\mu \mathrm{g} / \mathrm{ml})$} & & & {$[\mathrm{FN}](\mu \mathrm{g} / \mathrm{ml})$} & \\
\cline { 2 - 3 } & 0 & 50 & & 0 & 50 \\
\hline No block & 100 & $25 \pm 0.7$ & & 100 & $33 \pm 5.3$ \\
$10 \mathrm{mg} / \mathrm{ml} \mathrm{Hgb}$ & $5.3 \pm 1.4$ & $4.0 \pm 0.3$ & & $10 \pm 1.2$ & $6.0 \pm 0.9(n=6)$
\end{tabular}

Data are binding of $10 \mu \mathrm{g} / \mathrm{ml}{ }^{3} \mathrm{H}-\mathrm{FN}$ or ${ }^{3} \mathrm{H}-\mathrm{LM}$ to blocked and unblocked glass coverslips. Twelve millimeter round coverslips were completely covered with protein solutions as described for pattern production in Materials and Methods. The amount of ${ }^{3} \mathrm{H}-\mathrm{FN}$ and ${ }^{3} \mathrm{H}-\mathrm{LM}$ that bound to the coverslips was counted at each step in the process. Numbers are expressed as percentage of binding to uncoated glass $( \pm \mathrm{SEM}) . N=6$ for all ${ }^{3} \mathrm{H}-\mathrm{FN}$ measurements and $n=3$ for all ${ }^{3} \mathrm{H}$ LM measurements, except where indicated. 

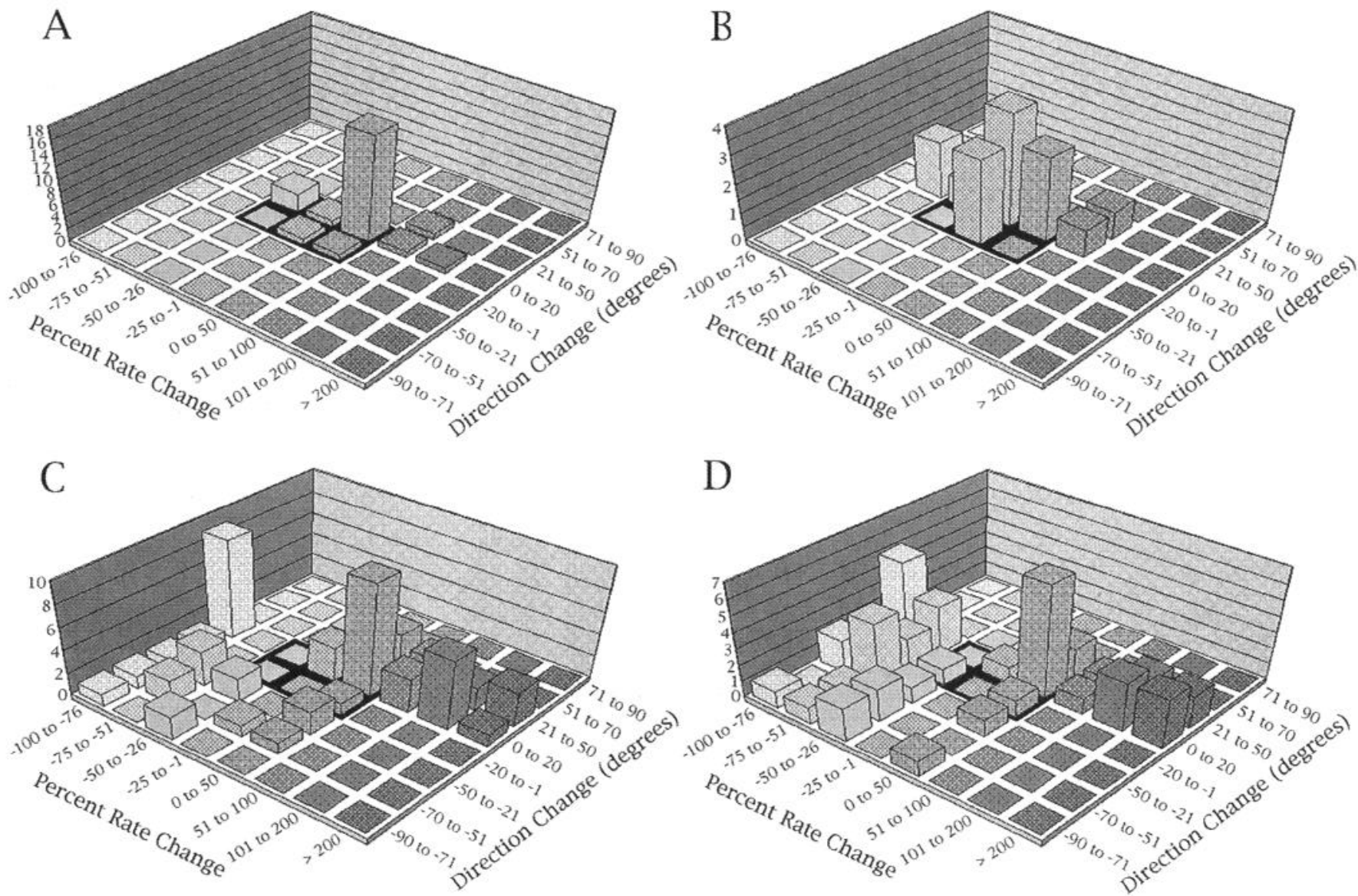

Figure 2. Three-dimensional plots correlating changes in the rate and direction of growth cone migration. Rate changes are expressed as percentage change from the initial rate (deceleration expressed as negative); observations were binned and plotted along the $x$-axis (left). Changes in the direction of migration were binned and plotted on the y-axis (right). Growth cones that oriented to take a more direct path across the border were expressed as a positive value and growth cones that turned away or took a more indirect path across the border were expressed as a negative value. The number of observations appears on the z-axis. The darkened area includes the limit of rate and direction changes we have defined as nonsignificant. $A$, LM-to-LM control. $B$, FN-to-FN control. $C$, LM-to-FN growth cones. $D$, FN-to-LM growth cones. In the control plots $(A$ and $B)$, most of the observations fall within the center of the graph, indicating only moderate changes in behavior occurred. On the other hand, the LM-to-FN $(C)$ and FN-to-LM $(D)$ plots show that these growth cones underwent more significant changes in behavior upon contact with the alternative substratum. In addition, the observations fall into two opposing quadrants, indicating that directional and migration rate changes are linked; that is, growth cones that reorient toward the border tend to increase their rate of migration, whereas growth cones that turn away from the border tend to decrease their rate of migration.

by clustering of observations into two opposing quadrants in Figure $2 C$; that is, growth cones contacting FN either accelerate and orient more directly toward FN (positive response), or decelerate and turn away from FN (negative response). Upon contact with FN, 37\% of LM-to-FN growth cones underwent significant positive behavioral changes, whereas $41 \%$ underwent significant negative behavioral changes. An example of a positive response of a growth cone to FN is shown in Figure 3. A few distant and transient filopodial contacts with FN were observed early (Fig. 3B, arrow). Fifty minutes later several new filopodial contacts (Fig. $3 F$, arrows) were made with FN, and these filopodia appeared to fuse and rapidly expand into a new leading edge of the now reoriented growth cone. The rate of neurite outgrowth is plotted in Figure $3 J$. On LM (Fig. $3 A-F$ ), this growth cone is predominately filopodial with few lamellipodia, whereas on FN (Fig. $3 H, I$ ) the growth cone appears flattencd and has fewer filopodia. During the process of orienting toward FN, this growth cone produced a small branch on LM.

Turning at a border occurred by either reorientation of the primary growth cone or by branching. Figure 4 illustrates a

Figure 3. Time-lapse sequence of a growth cone that crosses from LM (below) onto FN (above). A-I, The substratum border is indicated by arrowheads in all frames. Images are $10 \mathrm{~min}$ apart. The first observed filopodial contact with $\mathrm{FN}$ is at 10 min $(B$, arrow). This filopodial contact is retracted and the growth cone continues to migrate at the same rate (see $J$ ) and direction until several new filopodial contacts with FN are made $(F$, black arrows). These filopodia appear to rapidly fuse to form a nascent neurite $(F, G$, white arrows), at the tip of which a new growth cone forms. The growth cone accelerates and expands as it crosses onto FN $(G-I)$. A branched growth cone develops on LM from a portion of the primary growth cone $(F, G$, open arrows). Once fully across the border, the growth cone decelerates and adopts a flattened morphology $(I)$. Scale bar, $10 \mu \mathrm{m}$. J, Rate of migration of the growth cone in A-I. Letters correspond with the images above. This growth cone increased its rate of migration from $0.39 \mu \mathrm{m} / \mathrm{min}$ (points prior to position $F$ ) to $1.21 \mu \mathrm{m} / \mathrm{min}$ (points after position $F$ ) upon contact with FN. 

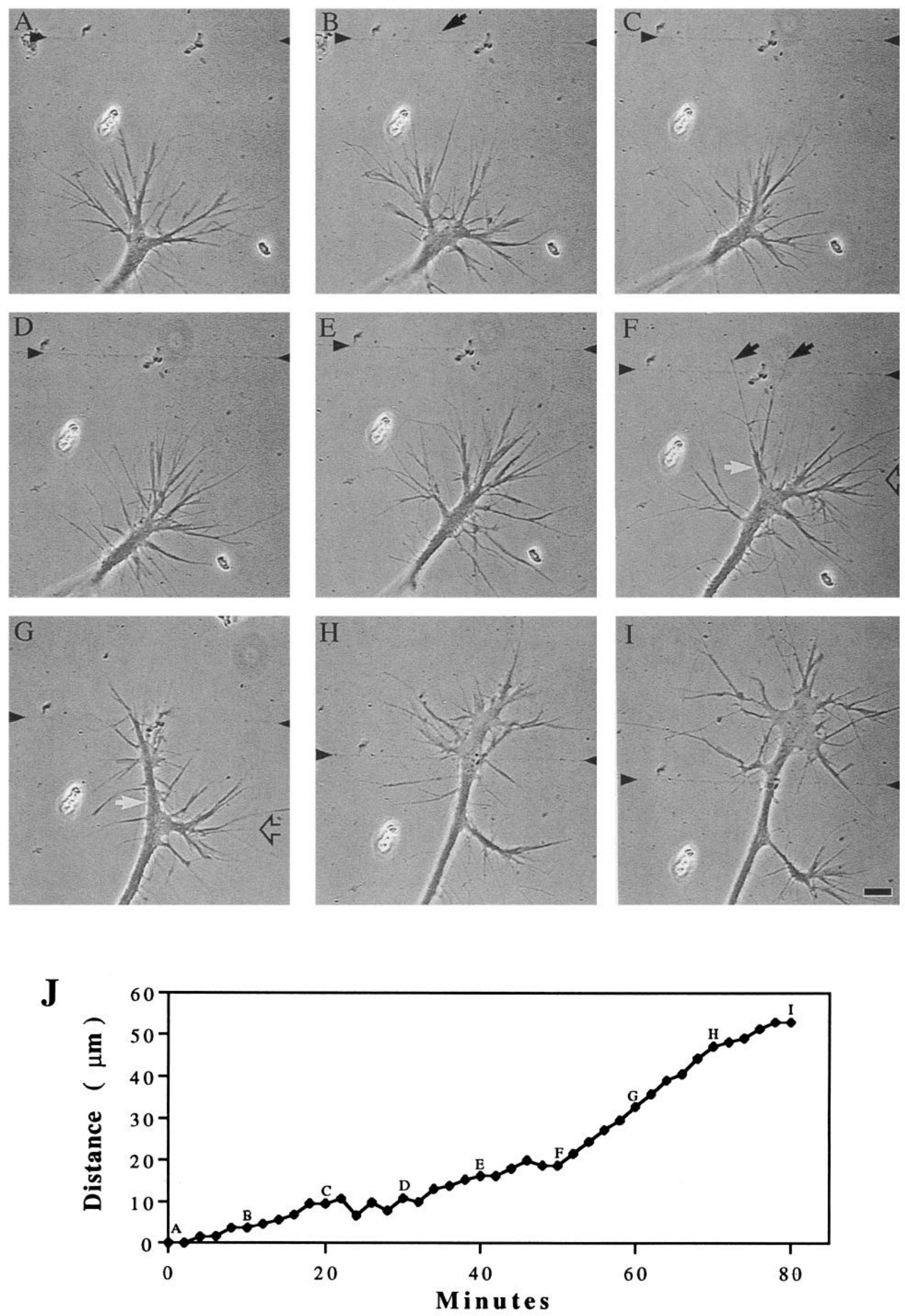

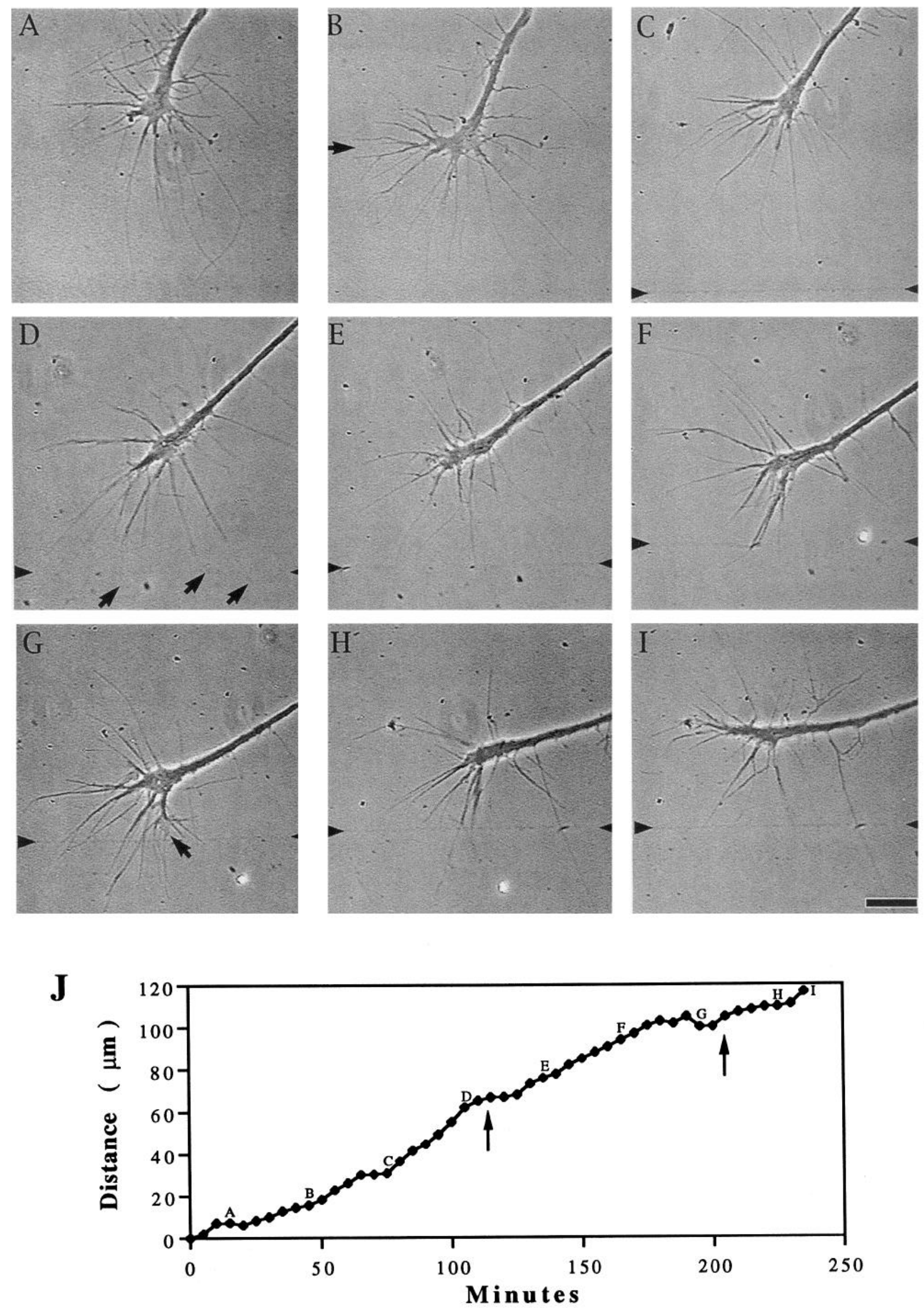
typical response of a growth cone turning away from FN. This growth cone made extremely long filopodial contacts with FN (earliest contacts observed prior to Fig. $4 B$, not shown) and showed initial signs of turning when the body of the growth cone was greater than $40 \mu \mathrm{m}$ away from the substratum border (Fig. $4 B$, arrow). As this growth cone approached the border it underwent transient decreases in its rate of migration (Fig. $4 J$, arrows) which were often associated with periods of apparently heightened filopodial sampling of FN (Fig. 4D,G). The periods of hcightened filopodial sampling were followed by further dcviation away from FN and an increased rate of neurite outgrowth. This growth cone eventually oriented parallel to the borderline, while maintaining filopodial contact with FN.

$F N$-to-LM growth cones. Many FN-to-LM growth cones underwent behavioral changes similar to those of the LM-to-FN growth cones. Fifty-nine percent of FN-to-LM growth cones ( $n$ $=66$ ) crossed onto $\mathrm{LM}, 32 \%$ turned at the border to remain associated with FN, and 9\% stopped at the border with LM for the remainder of the observation period (average observation time at border, $6.5 \mathrm{hr}$ ). For comparison, $94 \%$ of the FN-to-FN growth cones crossed the border $(n=18)$. Directional and elongation rate changes in response to contact with $\mathrm{LM}$ for 50 of the 66 growth cones observed are summarized in Figure $2 D$. Using the same criteria described above, $80 \%$ of the FN-to-LM growth cones compared to $26 \%$ of the FN-to-FN growth cones underwent significant changes in behavior upon contact with the substratum border. As with the LM-to-FN growth cones, changes in rate and direction of outgrowth were correlated, as indicated by the clustering of observations into two opposing quadrants in Figure 2D. Upon contact with LM, 28\% of growth cones underwent significant positive behavioral changes, whereas $52 \%$ underwent significant negative behavioral changes.

\section{Changes in growth cone behavior are initiated by flopodia}

The behavioral changes exhibited by the growth cones in Figures 3 and 4 occurred after only filopodial contact with $F N$, when the bodies of these growth cones were on LM, many micrometers from the substratum border. Analysis of the high-magnification records indicates that the LM-to-FN growth cones that crossed onto $\mathrm{FN}$ altered their behavior at an average distance of $7 \pm$ $1.5 \mu \mathrm{m}$ from the border $(n=14)$. LM-to-FN growth cones that turned at the border with FN began turning when the body of the growth cone was at an average of $13 \pm 4 \mu \mathrm{m}$ from the border $(n=11)$. Similarly, for FN-to-IM growth cones, the average distance to the border at the point the behavioral change began was $6 \pm 1.3 \mu \mathrm{m}$ for those that crossed onto LM $(n=17)$ and $13 \pm 3.1 \mu \mathrm{m}$ for those that turned away from LM $(n=9)$. These results show that filopodia initiate behavioral changes by the growth cone, suggesting that filopodia may be transducing environmental cues into intracellular signals.
Response of growth cones encountering a border between LM and $F N$ at decreasing angles of contact

In an earlier report, we suggested that the angle at which a growth cone contacted a border between LM and FN affected the behavior of an elongating neurite (Gomez and Letourneau, 1991). By examining fixed cultures, we found that for neurites that had turned at a border, the portion of the neurite proximal to the border was more likely to make a $<40^{\circ}$ angle with the border. Conversely, for neurites that had crossed a border, the portion of the neurite proximal to the border was more likely to make a $>40^{\circ}$ angle with the border. These results suggested that elongating neurites have a grcater probability of crossing a border if they contact the border at angles approaching perpendicular. This conclusion, however, was not supported by video records of living growth cones. Many neurites that contacted a border at a near perpendicular angle did not cross the border, but turned as much as $90^{\circ}$ to remain associated with the same substratum. Upon further examination of the video records we confirmed that the angle measurements made of fixed neurites did not reliably reflect the actual angle at which a growth cone had encountered a border. In other words, the angle of initial contact of a growth cone with a border is not necessarily maintained as the growth cone continues to migrate.

In order to better understand how growth cones approaching LM/FN borders at different angles respond to a substratum change, we correlated the angle of approach with the crossing or turning behavior of more than 120 growth cones (Table 2). Both LM-to-FN and FN-to-LM growth cones turned at the border with the alternate substratum regardless of the angle of approach (average angle of approach, $61^{\circ}$ and $64^{\circ}$, respectively). Along with those that turned, 14 growth cones stopped at the border for the remainder of the observation period (data not included in Table 2). Although we saw fewer neurites approach the border at the most indirect angles $\left(n=19\right.$ at $\leq 30^{\circ}$ ), among the growth cones observed we saw no correlation between the angle of approach and the probability of turning.

\section{Changes in growth cone-substratum close contacts do not predict the substratum of preferred outgrowth}

The extent to which a growth cone adheres to different ECM molecules may be one factor that influences its pathway selection (Letourneau, 1975). To test this hypothesis, we examined growth cones at the border between $\mathrm{LN}$ and FN using time-lapse interference reflection microscopy (IRM). As previously shown (Harris, 1973; Izzard and Lochner, 1976; Letourneau, 1979), the dark regions of an IRM image represent areas of close membrane apposition and greater adherence to the underlying substratum, whereas lighter areas represent regions of greater separation and reduced adherence.

Figure 4. Time-lapse sequence of a growth cone on LM (above) that turned at the border with FN (below). $A-I$, The substratum border is indicated by arrowheads in $C-I$ (the border is below the field in $A$ and $B$ ). Frames are 30 min apart, except for $I$ and $H$, which are 10 min apart. The field of view has been shifted many times to keep the growth cone in view. $A$, Forward-projecting filopodia extend greater than $40 \mu \mathrm{m}$ from the distal extent of the growth cone body and contact FN (not seen). $B$, New filopodia and veil protrude laterally from the growth cone (arrow), which results in a slight turn to a less direct approach toward the border (compare the angle the growth cone makes with respect to the $\mathrm{x}$-axis in $A$ vs $C$ ). The rate of migration of this growth cone decreased (see $J$ ) at times of apparent increased filopodial sampling of FN in $D$ and $G$ (arrows), after which the growth cone turned further $(E, I)$. In $G($ arrow) a veil extends toward FN, but it is later retracted $(H)$. Scale bar, $10 \mu \mathrm{m}$. $J$, Rate of migration of the growth cone in $A-I$. Letters correspond with the images above. Overall this growth cone underwent only a small decrease in its rate of migration $(0.54 \mu \mathrm{m} / \mathrm{min}$ prior to point $D, 0.41 \mu \mathrm{m} / \mathrm{min}$ after point $D)$. However, for brief periods larger drops in this growth cone's rate of migration (arrows) occurred and these rate changes were associated with periods of heightened filopodial sampling of FN ( $D$, $G$ ). 

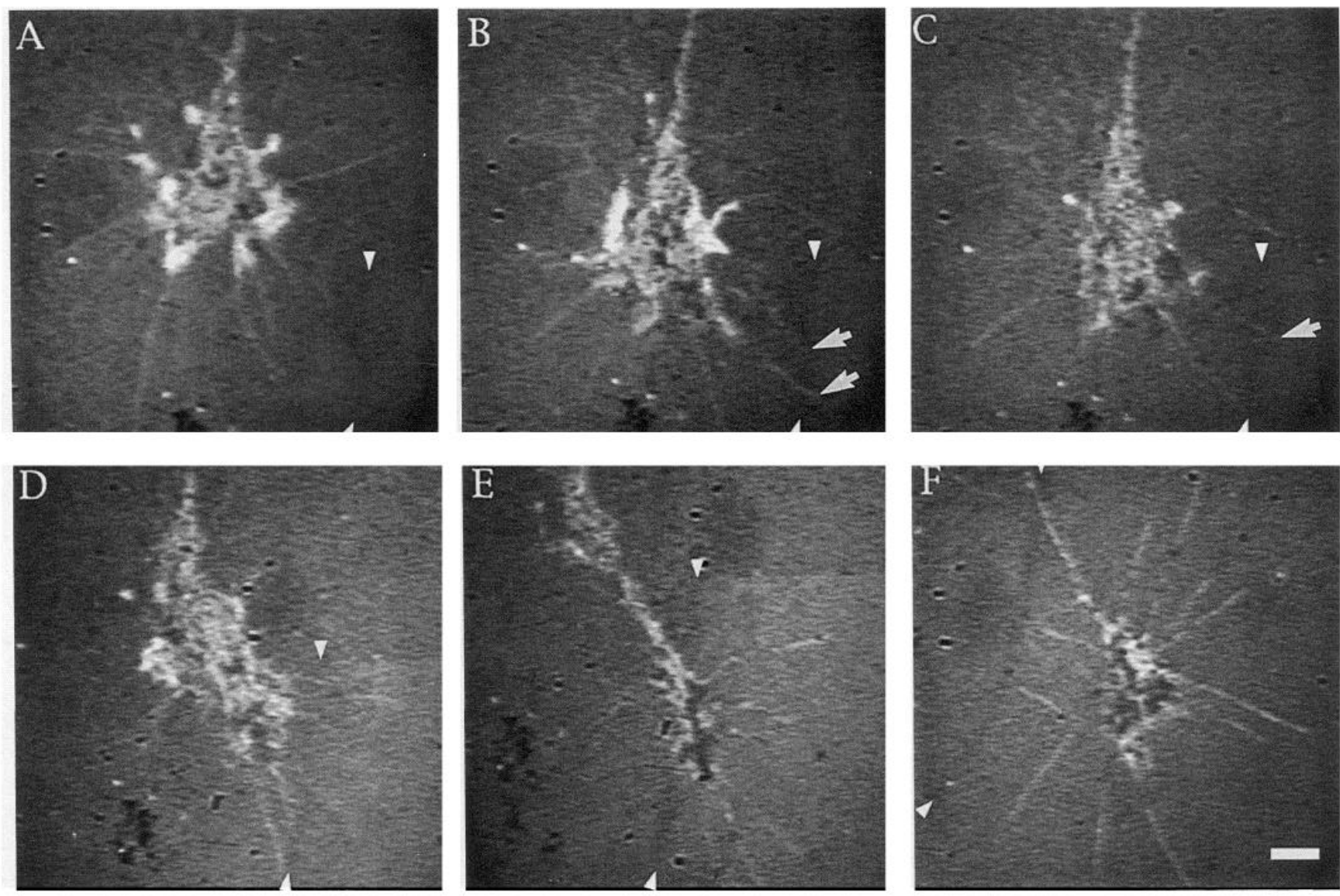

G

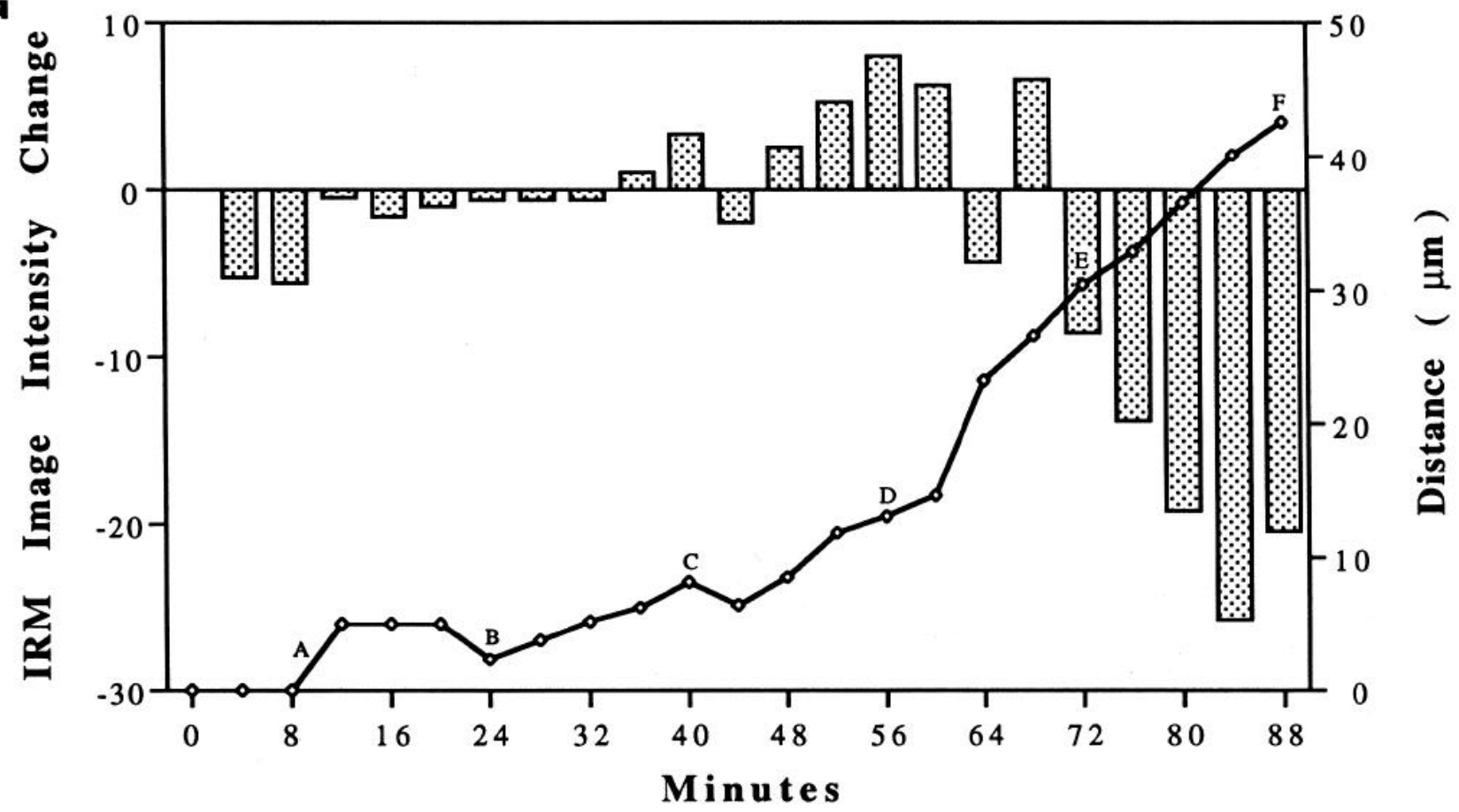

Figure 5. Time-lapse IRM sequence of a growth cone that crosses from LM (upper left) onto FN (lower right). A-F, The substratum border in this sequence projects vertically (arrowheads indicate border) at the point this growth cone crosses it. Images are approximately 15 min apart. After 


\begin{tabular}{|c|c|c|c|c|c|c|c|c|}
\hline \multirow[b]{2}{*}{ Angle } & \multicolumn{2}{|c|}{ LM-to-LM } & \multicolumn{2}{|c|}{ FN-to-FN } & \multicolumn{2}{|c|}{ LM-to-FN } & \multicolumn{2}{|c|}{ FN-to-LM } \\
\hline & Cross & Turn & Cross & Turn & Cross & Turn & Cross & Turn \\
\hline $10^{\circ}$ & 1 & 0 & 0 & 0 & 3 & 0 & 1 & 1 \\
\hline $20^{\circ}$ & 1 & 1 & 0 & 0 & 4 & 2 & 0 & 1 \\
\hline $30^{\circ}$ & 1 & 0 & 1 & 0 & 3 & 2 & 1 & 1 \\
\hline $40^{\circ}$ & 1 & 0 & 1 & 0 & 1 & 1 & 5 & 5 \\
\hline $50^{\circ}$ & 3 & 0 & 2 & 0 & 7 & 2 & 4 & 1 \\
\hline $60^{\circ}$ & 7 & 0 & 3 & 1 & 4 & 2 & 7 & 3 \\
\hline $70^{\circ}$ & 5 & 0 & 4 & 0 & 5 & 6 & 5 & 0 \\
\hline $80^{\circ}$ & 8 & 0 & 3 & 0 & 9 & 0 & 5 & 5 \\
\hline $90^{\circ}$ & 2 & 0 & 4 & 0 & 10 & 5 & 11 & 4 \\
\hline Totals & 29 & 1 & 17 & 1 & 46 & 20 & 39 & 21 \\
\hline
\end{tabular}

The angle that a growth cone approached and contacted a border did not influence its bchavior. Numbers indicate the number of growth cones observed to cross or turn at a border at a given angle of approach. Growth cones that stopped at the border are not included in this data set. On LM-to-LM and FN-to-FN control patterns, a large majority of growth comes crossed the border at all angles of approach. On the other hand, 30\% of the LM-to-FN and 35\% of the FN-toLM growth cones turned at the border with the alternative substratum, at various angles of approach. However, no consistent significant difference in the percentage of growth cones that turned at a border was seen at decreasing angles of approach.

Our results confirm a previous report that DRG growth cones express closer contacts when migrating on FN than on LM (Gundersen, 1988). Our new finding using time-lapse IRM is that contacts of a single growth cone change rapidly as the growth cone passes from one substratum onto another, such that a growth cone in contact with both substrata can show two patterns of contact. FN-to-LM growth cones that orient toward and accelerate onto LM simultaneously lose many close contacts, acquiring an IRM pattern typical for migration on LM. Conversely, as shown in Figure 5, LM-to-FN growth cones that orient toward and accelerate onto FN increase their total area of close contact and acquire an IRM pattern typical of migration on FN. Note that the change in the IRM pattern is coincident with the $\mathrm{LM} / \mathrm{FN}$ border, when this growth cone is spanning the border between LM and FN (Fig. $5 E$ ). Quantitative analysis of the average pixel intensity of IRM images from the sequence presented in Figure $5 A-F$ reveals both a decrease in the average pixel intensity and an increased rate of migration as this growth cone crosses onto FN (Fig. 5G). Growth cones crossing from FN onto LM showed an average increase in pixel intensity of $16 \pm 5 \%(n=5)$, while those crossing from LM onto FN decreased by an average of $11 \pm 2 \%(n=5)$.

Growth cones that turn at a border with FN or LM typically make many filopodial contacts on both substrata. The filopodial contacts seen over both LM and FN often appear similar under IRM optics, although differences may be difficult to resolve. In one instance, however, we observed an LM-to-FN growth cone that turned at the border with FN, despite making many very stable and close filopodial contacts onto the FN-treated substrata (Fig. 6). This observation indicates that while filopodial contact can be sufficient to initiate changes in growth cone behaviors (see Fig. 3), close filopodial-substratum apposition is not sufficient to reorient the growth conc. Our results using IRM suggest that there is no direct correlation between the degree of substratum contact and choice of substratum.

\section{Discussion}

Previous studies of the effects of patterned substrata on neurite outgrowth (Hammarback et al., 1985; Gundersen, 1987; Walter et al., 1987; Lemmon et al., 1992) did not assess the detailed behavior of growth cones and filopodia at substratum borders. In the present study, we analyzed the behaviors of individual dorsal root ganglion neuron growth cones at a choice point between two growth-promoting substrata, LM and FN. We draw three conclusions from this study. First, growth cones readily detect a change in ECM substrata, and respond in a manner that we interpret as an active choice to either remain on their original substratum, or to cross onto the alternative substratum. Second, changes in growth cone behavior are initiated by filopodia that extend forward and contact the alternate substratum. Third, selection of one substratum over the other is not correlated with the degree of growth cone-substratum contact.

\section{Growth cone behavior changes at an $L M / F N$ border}

We found that $79 \%$ of all DRG growth cones changed their behavior upon encountering an LM/FN border. To distinguish this behavior from random or stochastic changes (Katz et al., 1984) or from potential physical effects of the borders, we analyzed growth cone behavior at FN/FN and LM/LM borders. Only $26 \%$ of growth cones at an FN/FN and $12 \%$ of growth

several filopodial contacts with FN $(B, C$, arrows), this growth cone orients toward the border $(C, D)$ and accelerates (see $G)$ as it crosses onto the FN-treated surface. When this growth cone was spanning the border, it somctimes exhibited two pattcrns of close contacts, which changed at points coincident with the border $(E)$. This growth cone continued to migrate onto $\mathrm{FN}$, at an elevated rate of outgrowth, and altered morphology. Scale bar, $5 \mu \mathrm{m}$. $G$, Rate of migration (line) and average IRM image intensity change (bar) of the growth cone in $A-F$. Letters correspond with the images above. The average pixel intensity of growth cone images was normalized and presented as the difference between subsequent image measurements. At the point this growth cone crosses the border onto FN, it simultaneously increases its rate of migration and extent of close contact (lower image intensity). 

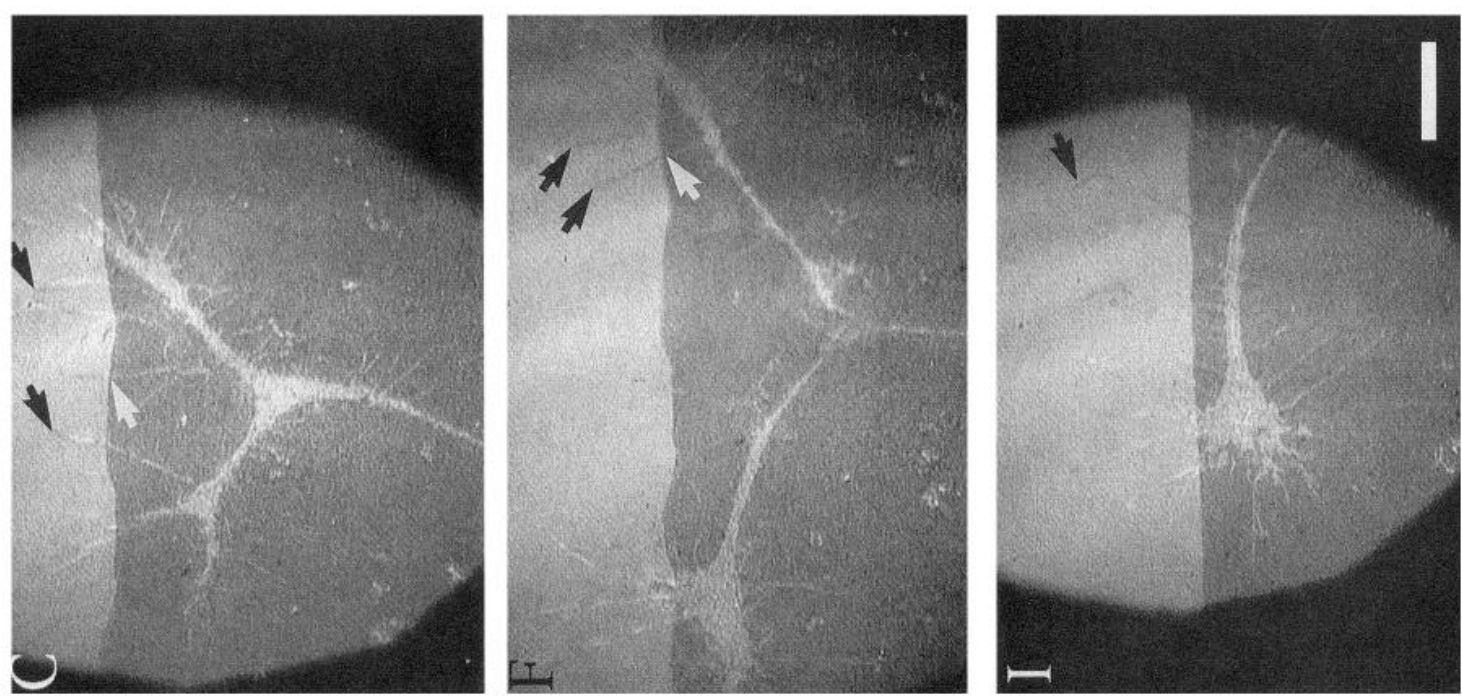

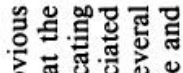

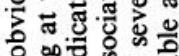

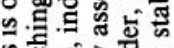

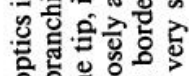

응응응

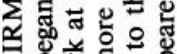

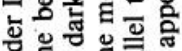

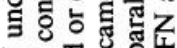

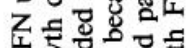

응 들

的目是

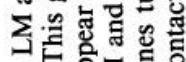

들

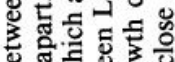

ब

돈

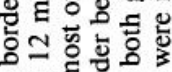
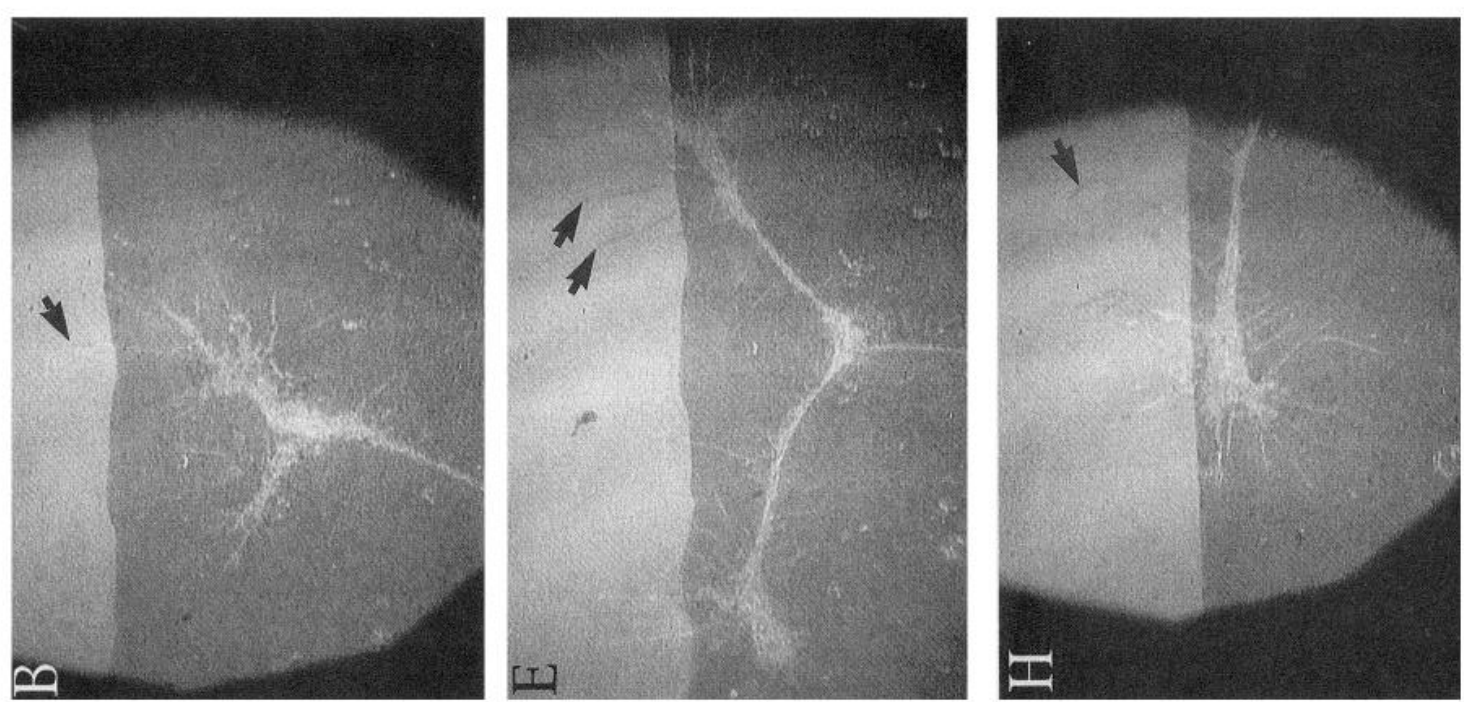

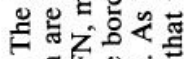

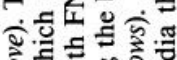

을

过

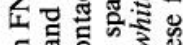

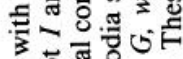

总要

항 영 닌

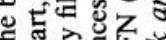

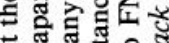

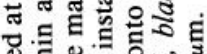

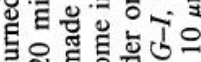

>⿻

过

今. ⿷匚

递它

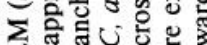

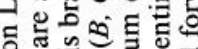
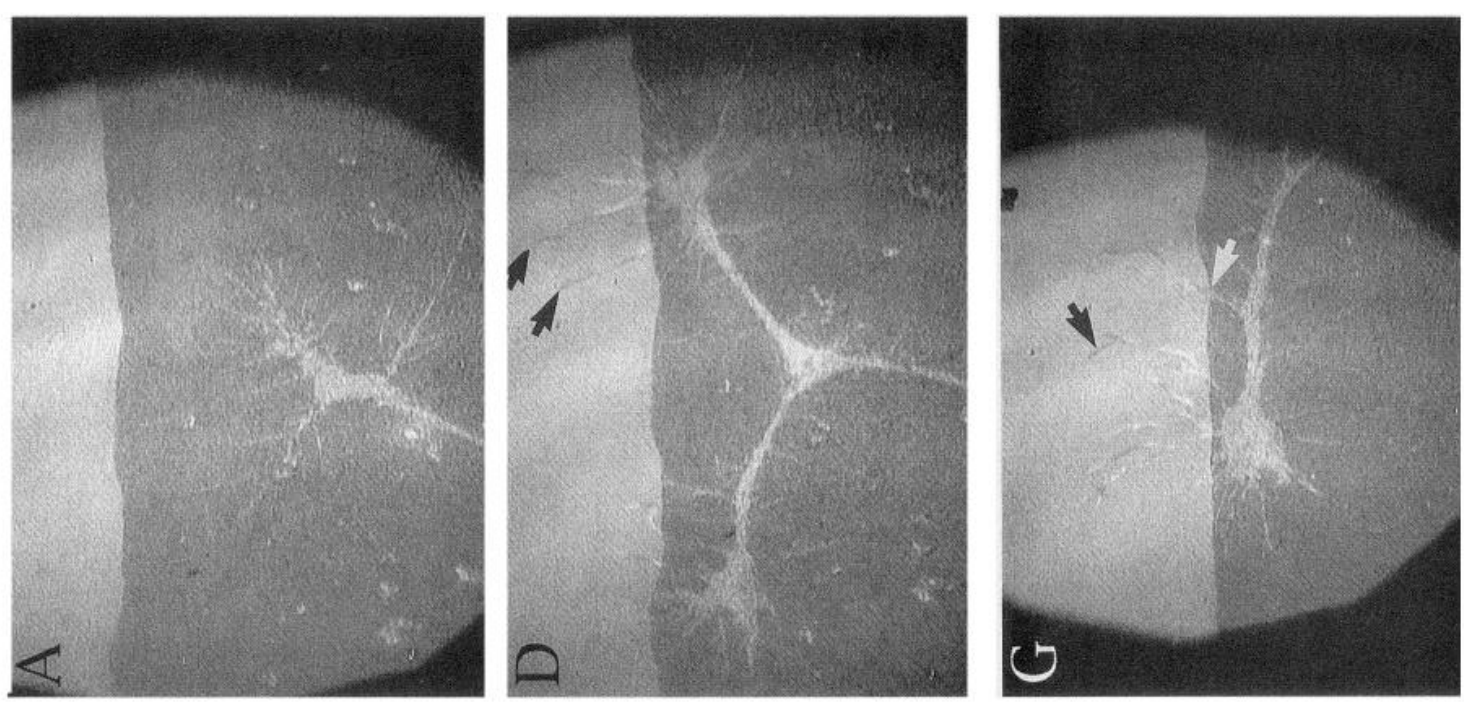

幽密

응 은

들

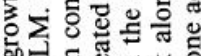

的

형ㅎㅇ

돈

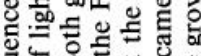
政 论式 政 on

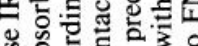
品 论

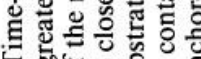

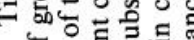
○. 을

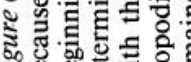

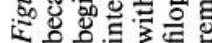


cones at an LM/LM border exhibited behavioral changes that we defined as significant. Thus, we conclude that most DRG growth cones respond to a change in the ECM substratum, whether they are extending originally on FN or LM. In addition, there is an important correlation between changes in growth cone orientation and rate of migration (Fig. 2). Growth cones that crossed a border increased their rate of migration, while growth cones that turned away from a border decreased their rate of migration. Less then $2 \%$ of the growth cones exhibited opposing behaviors (e.g., oriented toward and decelerated, or turned and accelerated). Importantly, changes in growth cone behavior were not brief responses, but rather they were sustained changes that significantly altered growth cone migration.

Growth cone steering at a border between LM and FN occurred by several different processes, all of which have been observed in other systems. In most cases, growth cones altered their direction by localized changes in protrusion of cytoplasm toward filopodia and veil (e.g., Fig. $4 B$ ), as has been described in detail for growth cone advance in vitro (Bray and Chapman, 1985; Goldberg and Burmeister, 1986) and in vivo (O'Connor et al., 1990). Less frequently, we observed growth cone steering by the selective regression of a veil (Fig. 4G), a process that occurred only when growth cones turned away from a border. The selective regression of veils and growth cones has been described previously on patterned substrata (Burmeister and Goldberg, 1988) and upon contact of motor growth cones with sclerotome cells in vitro (Oakley and Tosney, 1993). Lastly, growth cone steering occasionally resulted from the rapid expansion of a single filopodium into a nascent neurite. This process, similar to that described in the grasshopper limb (O'Connor et al., 1990), occurred only when filopodia contacted a preferred substratum. This process is shown in Figure 3, where two filopodia apparently fused (Fig. $3 F, G$ ) to form a nascent neurite, at the tip of which a new growth cone formed.

Although most DRG growth cones detect a substratum change, and choose to migrate on LM or FN, our results do not indicate that DRG growth cones comprise a single population that prefers FN or LM. This is unlike other studies, where the behavior of migrating cells or growth cones was interpreted as a consistently observed preference for one substratum versus another (Hammarback et al., 1985; Gundersen, 1987; Walter et al., 1987; Calof and Lander, 1991). Perhaps cultured DRG neurons comprise a heterogeneous population, including some neurons with neurites that prefer FN at an LM/FN border, and other neurons whose growth cones prefer LM. Such preferences may be intrinsic to cultured DRG neurons, or the differences may arise as a result of the in vitro conditions. Subsets of DRG growth cones may express distinct combinations of cell surface receptors. Differential expression of receptors for adhesion molecules and trophic factors may mediate growth cone migration along the different pathways taken by the central and peripheral axons of each DRG neuron (Mu et al., 1993). Additional evidence suggests that cutaneous afferents and muscle afferents have distinct pathfinding abilities (Lance-Jones and Landmesser, 1981; Scott, 1988; Maisonpierre et al., 1990; LoPresti and Scott, 1992). DRG neurons may also differ because the expression of surface receptors may change from the time of growth cone formation, through pathfinding, and, finally, after reaching a target (Hall et al., 1987; Cohen et al., 1989; Lefcort et al., 1992). Since DRG neurons are not synchronized in these events at E10, when they are cultured, these differences may contribute to heterogeneity of DRG growth cones.
DRG neurons and their growth cones may also become heterogeneous, as the result of interactions with components of our in vitro system. For example, we add NGF but not other neurotrophins to our culture media. Since DRG neurons express different arrays of $t r k$ receptors (Carroll et al., 1992), this could lead to differential induction of cellular factors that influence neurite outgrowth on LN or FN. In addition, DRG growth cones may contact other neurons, Schwann cells, fibroblasts, and ECM components and these interactions may modulate the expression or activity of growth cone surface components (reviewed in Damsky and Werb, 1992; Ginsberg et al., 1992; Hynes, 1992; Schweighoffer and Shaw, 1992).

Our results indicate that local discontinuities of two ECM components can direct DRG neurite outgrowth and can affect growth cone velocity and morphology. This is in contradiction to previous studies suggesting that ECM components (reviewed in Reichardt and Tomaselli, 1991) and cell adhesion molecules (Lemmon et al., 1992) are permissive for neurite outgrowth, but do not provide instructive information to direct neurite outgrowth. Our findings also show that DRG growth cones can respond differently to the same change in ECM substratum, suggesting that patterns of LM and FN could function as instructive pathways in vivo. Further, many of the behavioral changes we observed at $\mathrm{LM} / \mathrm{FN}$ borders have been reported at characteristic positions along many neuronal migratory pathways in vivo (Raper et al., 1983; Tosney and Landmesser, 1985b; Caudy and Bentley, 1986; Eisen et al., 1986; Godement et al., 1990). Therefore, differentially distributed ECM molecules may account for some of the behavioral changes observed in vivo.

\section{Filopodia first detect a change in ECM substratum}

Filopodia have been shown to play an important navigational role for growth cones both in vitro (Kapfhammer et al., 1986; Bandtlow et al., 1990; Letourneau et al., 1990, 1991) and in vivo (Raper et al., 1983; Bastiani et al., 1984; Bentley and Toroian-Raymond, 1986; O'Connor et al., 1990; Letourneau et al., 1991; Chien et al., 1993). As a growth cone approaches a border, filopodia extend as much as $50 \mu \mathrm{m}$, and interact with the alternate ECM molecule (Figs. 3-6). Such interactions produced behavioral changes in the parent growth cone while it was still on its original substratum. At high magnification, we measured the distance between the growth cone body and the substratum border, when a change in behavior was initiated. Growth cones that crossed from I.M onto FN or vice versa initiated the behavior change (an increased rate of migration and/or a reorientation toward the border) at an average distance of $7 \mu \mathrm{m}$ from the border, whereas growth cones that turned to remain on their original substratum began turning at an average distance of $13 \mu \mathrm{m}$ from the border. Importantly, filopodial contact with the alternative substratum always preceded a change in growth cone behavior. It is unknown why growth cones that turn at a border initiate behavior changes at a greater distance than growth cones that cross a border; however, it is possible that directional changes are initiated more quickly than rate changes.

How could filopodial contacts change growth cone behavior? One possibility is that filopodia have ECM receptors that are activated by binding to LM or FN and generate transmembrane signals that pass to the growth cone to change motile behavior. Several receptors for ECM and cell adhesion molecules have been localized to growth cones, including some that are concentrated on filopodia (Van den Pol et al., 1986; Letourneau 
and Shattuck, 1989). The integrin family of heterodimeric cell surface receptors are a particularly important class of ECM receptors. Integrins containing the $\beta 1$ subunit, some of which bind LM and FN (reviewed in Reichardt and Tomaselli, 1991; Hynes, 1992; Letourneau et al., 1992; Reichardt, 1992), are expressed by DRG growth cones and are often concentrated at the tips of filopodia (Letourneau and Shattuck, 1989). Although at least four different $\beta 1$-containing integrins have been implicated in DRG growth cone migration on LM and FN (Reichardt, 1992; Tomaselli et al., 1993), these receptor subtypes have not been shown to be differentially expressed by subpopulations of growth cones or filopodia.

Recent pharmacological findings support a sensory role for adhesive interactions of growth cone filopodia. Several cell adhesion molecules and ECM binding integrin receptors have been shown to promote neurite outgrowth by activating second messenger systems that affect cytoskeletal polymerization and cell behavior (reviewed in Damsky and Werb, 1992; Hynes, 1992; Hynes and $I$ ander, 1992). In particular, integrin activation has been implicated in the fluctuation of intracellular messengers such as calcium (Jaconi et al., 1991), cAMP (Nathan and Sanchez, 1990), and pH (Schwartz et al., 1989, 1991), as well as protein kinase C activation (Bixby, 1989) and tyrosine phosphorylation (Guan et al., 1991; Kornberg et al., 1991). Therefore, activation of integrin receptors on the tips of filopodia could produce changes in diffusible second messengers that affect the body of a growth cone. Recently, growth cone filopodia were directly shown to possess the necessary signal transduction mechanisms to allow autonomous responses to environmental stimuli (Davenport et al., 1993).

How may filopodia-based intracellular signaling result in growth cone steering? Perhaps forward-projecting filopodia that cross a border transmit new signals to the growth cone, while more lateral filopodia continue to interact with the original substratum. In an environment of spatially segregated ex tracellular ligands, brief asymmetries of intracellular signals may arise within the growth cone. Thus, a few filopodia, interacting with a new substratum, may produce intracellular signals that are sufficiently strong or amplified, so as to dominate the continued signals received from the lateral filopodia. It would be interesting to know whether receptor distribution and/or transmembrane signals are different for forward-projecting versus lateral-projecting filopodia.

\section{Does adhesion play a role in growth cone steering?}

It has been suggested that guidance of growth cones could be due to local variations in substratum adhesivity, possibly acting to stabilize protrusions and provide anchorage for mechanochemical force (Harris, 1973; Letourneau, 1975, 1979; Hammarback et al., 1988; O'Connor et al., 1990). However, other studies indicate that growth cone-to-substratum adhesion does not determine substratum preference (Gundersen, 1987, 1988; Calof and Lander, 1991; Lemmon et al., 1992). Our results using time-lapse IRM argue that receptors for LM and FN do not function equally in mediating growth cone-substratum interactions. Instead, it appears that the adhesive nature of receptors may be only one factor in the control of growth cone migration.

IRM is a reliable indicator of cell-substratum adhesion (Harris, 1973; Izzard and Lochner, 1976; Gundersen, 1988; Calof and Lander, 1991; Lemmon et al., 1992). By observing growth cones using time-lapse IRM at the border between a highly adhesive molecule, FN, and a less adhesive molecule, LM, we have found that selection of one substratum over another does not necessarily involve achieving the highest degree of growth cone-to-substratum contact. This conclusion is based on two behaviors. (1) Some growth cones oriented toward and accelerated onto FN, coming into closer contact with the substratum (Fig. 5), as indicated by an $11 \pm 2 \%$ decrease in the average pixel intensity of the IRM images. Other growth cones oriented toward and accelerated onto LM, decreasing contact with the substratum, indicated by a $16 \pm 5 \%$ increase in the average pixel intensity of the IRM images. (2) Growth cones turned at the border with FN to remain on LM (Fig. 6), despite having many close filopodial and lamellipodial contacts with FN.

Neuronal growth cones (Fig. $5 E$ ), as well as non-neuronal cells (i.e., Schwann cells, fibroblasts, and neuroblastoma cells, not shown), spanning an LM/FN border exhibited a precise change in the pattern and degree of close contact, indicating that as a growth cone migrates onto a new substratum it concomitantly reorganizes its associations with that substratum. Perhaps along with local differences in the involvement of adhesive receptors, there are local differences in transmembrane signaling, which underlie the ability of filopodia contacts to regulate growth cone steering.

\section{Conclusions}

Presented with a choice between LM and FN, DRG growth cones exhibit behavioral changes indicating that they prefer one substratum over another. Further, DRG growth cones appear heterogeneous in their preference for LM or FN, indicating that subpopulations of DRG neurons may exist. Behavioral changes began after filopodial contact with the alternative ECM component, indicating that filopodia provide sensory input that regulates growth cone migration. Finally, using IRM we conclude that substratum preference is not dependent on achieving the highest degree of growth cone-substratum close contact. Taken together, this study presents evidence that localized distribution of ECM components can direct DRG neurite outgrowth in a manner that may be determined by the receptors and associated second messenger systems expressed by the growth cone and its filopodia.

\section{References}

Bandtlow C, Zachleder T, Schwab ME (1990) Oligodendrocytes arrest neurite outgrowth by contact inhibition. J Neurosci 10:3837-3848.

Bastiani MJ, Raper JA, Goodman CS (1984) Pathfinding by neuronal growth cones in grasshopper embryos. III. Selective affinity of the $G$ growth cone for the P cells within the A/P fascicle. J Neurosci 4:23112328 .

Bentley D, Toroian-Raymond A (1986) Disoriented pathfinding by pioneer neurone growth cones deprived of filopodia by cytochalasin treatment. Nature 323:712-715.

Bixby JL (1989) Protein kinase C is involved in laminin stimulation of neurite outgrowth. Neuron 3:287-297.

Bonhoeffer F, Huf J (1982) In vitro experiments on axon guidance demonstrating an anterior-posterior gradient on the tectum. EMBO J $1: 427-431$.

Bovolenta P, Mason CA (1987) Growth cone morphology varies with position in the developing mouse visual pathway from retina to first targets. J Neurosci 7:1447-1460.

Bray D (1982) Filopodial contraction and growth cone guidance. In: Cell behavior (Bellairs R, Curtis A, Dunn G, eds), pp 299-317. Cambridge: Cambridge UP.

Bray D, Chapman K (1985) Analysis of microspike movements on the neuronal growth cone. J Neurosci 5:3204-3213.

Buck CA, Horwitz AF (1987) Cell surface receptors for extracellular matrix molecules. Annu Rev Cell Biol 3:179-205. 
Burmeister DW, Goldberg DJ (1988) Micropruning: the mechanism of turning of Aplysia growth cones at substrate borders in vitro. $\mathrm{J}$ Neurosci 8:3151-3159.

Calof AL, Lander AD (1991) Relationship between neuronal migration and cell-substratum adhesion: laminin and merosin promote olfactory neuronal migration but are anti-adhesive. J Cell Biol 115 . $779-794$

Carbonetto S, Gruver MM, Turner DC (1983) Nerve fiber growth in culture on fibronectin, collagen and glycosaminoglycan substrates. J Neurosci 3:2324-2335.

Caroni P, Schwab ME (1988) Antibody against myelin-associated inhibitor of neurite growth neutralizes nonpermissive substrate properties of CNS white matter. Neuron 1:85-96.

Carroll SL, Silos-Santiago I, Frese SE, Ruit KG, Milbrandt J, Snider WD (1992) Dorsal root ganglion neurons expressing trk are selectively sensitive to NGF deprivation in utero. Neuron 9:779-788.

Caudy M, Bentley D (1986) Pioneer growth cone steering along a series of neuronal and non-neuronal cues of different affinities. J Neurosci 6:1781-1795.

Chang S, Rathien FG, Raper JA (1987) Extension of neurites on axons is impaired by antibodies against specific neural cell surface glycoproteins. J Cell Biol 104:355-362.

Chien C, Rosenthal DE, Harris WA, Holt CE (1993) Navigational errors made by growth cones without filopodia in the embryonic Xenopus brain. Neuron 11:237-251.

Cohen J, Nurcombe V, Jeffrey P, Edgar D (1989) Developmental loss of functional laminin receptors on retinal ganglion cells is regulated by their target tissue, the optic tectum. Development 107:381-387.

Cole GJ, McCabe CF (1991) Identification of a developmentally regulated keratan sulfate proteoglycan that inhibits cell adhesion and neurite outgrowth. Neuron 7:1007-1018.

Damsky CH, Werb Z (1992) Signal transduction by integrin receptors for extracellular matrix: cooperative processing of extracellular information. Curr Opin Cell Biol 4:772-781.

Davenport RW, Kater SB (1992) Local increases in intracellular calcium elicit local filopodial responses in Helisoma neuronal growth cones. Neuron 9:405-416.

Davenport RW, Dou P, Rehder V, Kater SB (1993) A sensory role for neuronal growth cone filopodia. Science 361:721-724.

Doherty P, Ashton SV, Moore SE, Walsh FS (1991) Morphoregulatory activities of NCAM and N-cadherin can be accounted for by $\mathrm{G}$ protein-dependent activation of $\mathrm{L}$ - and $\mathrm{N}$-type neuronal $\mathrm{Ca}^{2+}$ channels. Cell 67:21-33.

Doherty P, Singh A, Rimon G, Bolsover SR, Walsh FS (1993) Thy-1 antibody-triggered neurite outgrowth requires an influx of calcium into neurons via $\mathrm{N}$ - and L-type calcium channels. J Cell Biol 122: 181-189.

Eisen JS, Myers PZ, Westerfield M (1986) Pathway selection by growth cones of identified motoneurones in live zebra fish embryos. Nature 320:269-271.

Ginsberg MH, Du X, Plow EF (1992) Inside-out integrin signalling. Curr Opin Cell Biol 4:766-771.

Godement P, Salaun J, Mason CA (1990) Retinal axon pathfinding in the optic chiasm: divergence of crossed and uncrossed fibers. Neuron 5:173-186.

Goldberg DJ, Burmeister DW (1986) Stages in axon formation: observations of Aplysia axons in culture using video-enhanced contrastdifferential interference contrast microscopy. J Cell Biol 103:19211931.

Gomez TM, Letourneau PC (1991) Soc Neurosci Abstr 17.

Guan JL, Trevithick JE, Hynes RO (1991) Fibronectin/integrin interaction induces tyrosine phosphorylation of a $120 \mathrm{kDa}$ protein. Cell Regul 2:951-964.

Gundersen RW (1987) Response of sensory neurites and growth cones to patterned substrata of laminin and fibronectin in vitro. Dev Biol $121: 423-431$

Gundersen RW (1988) Interference reflection microscopic study of dorsal root growth cones on different substrates: assessment of growth cone-substrate contacts. J Neurosci Res 21:298-306.

Gundersen RW, Barrett JN (1979) Neuronal chemotaxis: chick dorsalroot axons turn toward high concentrations of nerve growth factor Science 206:1079-1080.

Hall DE, Neugebauer KM, Reichardt LF (1987) Embryonic neural retinal cell response to extracellular matrix proteins: developmental changes and effects of the cell substratum attachment antibody (CSAT). J Cell Biol 104:623-634.

Hammarback JA, Palm SL, Furcht LT, Letourneau PC (1985) Guidance of neurite outgrowth by pathways of substratum-adsorbed laminin. J Neurosci Res 13:213-220.

Hammarback IA, McCarthy JB, Palm SL, Furcht LT, Letourneau PC (1988) Growth cone guidance by substrate-bound laminin pathways is correlated with neuron-to-pathway adhesivity. Dev Biol 126:2939

Harlow E, Lane D (1988) Antibodies: a laboratory manual. Cold Spring Harbor, NY: Cold Spring Harbor Laboratory.

Harris WA (1973) Location of cellular adhesions to solid substrata. Dev Biol 35:83-96.

Harris WA (1989) Local positional cues in the neuroepithelium guide retinal axons in embryonic Xenopus brain. Nature 339:218-221.

Harrison RW (1914) The reaction of embryonic cells to solid structures. J Exp Zool 17:521-544.

Herbst TJ, McCarthy JB, Tsilibary EC, Furcht LT (1988) Differential effects of laminin, intact type IV collagen, and specific domains of type IV collagen on endothelial cell adhesion and migration. J Cell Biol 106:1365-1373.

Hynes RO (1992) Integrins: versatility, modulation, and signaling in cell adhesion. Cell 69:11-25.

Hynes RO, Lander AD (1992) Contact and adhesive specificities in the associations, migrations, and targeting of cells and axons. Cell 68: 303-322.

Izzard CS, Lochner LR (1976) Cell-to-substrate contacts in living fibroblasts: an interference reflexion study with an evaluation of the technique. J Cell Sci 21:129-159.

Jaconi MEE, Theler JM, Schlegel W, Appel RD, Wright SD, Lew PD (1991) Multiple elevations of cytosolic-free $\mathrm{Ca}^{2+}$ in human neutrophils: initiation by adherence receptors of the integrin family. J Cell Biol 112:1249-1257.

Jentoft N, Dearborn D (1979) Labeling of proteins by reductive methylation using sodium cyanoborohydride. J Biol Chem 254:4359-4365.

Kapfhammer JP, Grunewald BE, Raper JA (1986) The selective inhibition of growth conc advancement of specific neurites in culture. J Neurosci 6:2527-2534.

Katz MJ, George EB, Gilbert LJ (1984) Axonal elongation as a stochastic walk. Cell Motil 4:351-370.

Kolodkin AL, Matthes DJ, O'Connor TP, Patel NH, Admon A, Bentley D, Goodman CS (1992) Fasciclin IV: sequence, expression, and function during growth cone guidance in the grasshopper embryo. Neuron 9:831-845.

Kornberg LJ, Earp HS, Turner CE, Prockop C, Juliano RL (1991) Signal transduction by integrins: increased protein tyrosine phosphorylation caused by clustering of $\beta_{1}$ integrins. Proc Natl Acad Sci USA 88:8392-8396.

Lagenaur C, Lemmon V (1987) An L1-like molecule, the 8D9 antigen, is a potent substrate for neurite extension. Proc Natl Acad Sci USA 84:7753-7757.

Lance-Jones C, Landmesser L (1981) Pathway selection by chick lumbosacral motoneurons during normal development. Proc R Soc Lond [Biol] 214:1-18.

Lefcort F, Venstrom K, McDonald JA, Reichardt LF (1992) Regulation of expression of fibronectin and its receptor, $\alpha 5 \beta 1$, during development and regeneration of peripheral nerve. Development 116 : 767-782.

Lemmon V, Burden SM, Payne HR, Elmslie GJ, Hlavin ML (1992) Neurite growth on different substrates: permissive versus instructive influences and the role of adhesive strength. J Neurosci 12:818-826.

Letourneau PC (1975) Cell-to-substratum adhesion and guidance of axonal elongation. Dev Biol 44:92-101.

Letourneau PC (1979) Cell-substratum adhesion of neurite growth cones, and its role in neurite elongation. Exp Cell Res 124:127-138.

Letourneau PC (1981) Immunocytochemical evidence for colocalization in neurite growth cones of actin and myosin and their relationship to cell-substratum adhesions. Dev Biol 85:113-122.

Letourneau PC, Shattuck TA (1989) Distribution and possible interactions of actin-associated proteins and cell adhesion molecules of nerve growth cones. Development 105:505-519.

Letourneau PC, Shattuck TA, Roche FK, Takeichi M, Lemmon V (1990) Nerve growth cone migration onto Schwann cells involves the calcium-dependent adhesion molecule, N-cadherin. Dev Biol 138:430442. 
Letourneau PC, Kater SB, Macagno ER, eds (1991) The nerve growth cone. New York: Raven.

Letourneau PC, Condic ML, Snow DM (1992) Extracellular matrix and neurite outgrowth. Curr Opin Gen Dev 2:625-634.

LoPresti P, Scott SA (1992) Cutaneous and muscle afferents in vitro: different requirements for survival factors. Soc Neurosci Abstr 18: 919.

Ludueña MA (1973) The growth of spinal ganglion neurons in serumfree medium. Dev Biol 33:470-476.

Lumsden AG, Davies AM (1986) Chemotropic effect of specific target epithelium in the developing mammalian nervous system. Nature 323:538-539.

Maisonpierre PC, Belluscio L, Squinto S, Ip NY, Furth ME, Lindsay RM, Yancopoulos GD (1990) Neurotrophin-3: a neurotrophic factor related to NGF and BDNF. Science 247:1446-1451.

Matsunaga M, Hatta K, Nagafuchi A, Takeichi M (1988) Guidance of optic nerve fibres by $\mathrm{N}$-cadherin adhesion molecules. Nature 334 : 62-64.

McCarthy JB, Hagen ST, Furcht LT (1986) Human fibronectin contains distinct adhesion- and motility-promoting domains for metastatic melanoma cells. J Cell Biol 102:179-188.

Mu X, Silos SI, Carroll SL, Snider WD (1993) Neurotrophin receptor genes are expressed in distinct patterns in developing dorsal root ganglia. J Neurosci 13:4029-4041.

Nathan C, Sanchez E (1990) Tumor necrosis factor and CD11/CD18 $\left(\beta_{2}\right)$ integrins act synergistically to lower cAMP in human neutrophils. J Cell Biol 111:2171-2181.

Oakley RA, Tosney KW (1993) Contact-mediated mechanisms of motor axon segmentation. J Neurosci 13:3773-3792.

O'Connor TP, Bentley D (1993) Accumulation of actin in subsets of pioneer growth cone filopodia in response to neural and epithelial guidance cues in situ. J Cell Biol 123:935-948.

O'Connor TP, Duerr JS, Bentley D (1990) Pioneer growth cone steering decisions mediated by single filopodial contact in silu. J Neurosci 10:3935-3946.

O'Leary DD, Heffner CD, Kutka L, Lopez ML, Missias A, Reinoso BS (1991) A target-derived chemoattractant controls the development of the corticopontine projection by a novel mechanism of axon targeting. Development [Suppl] 2:123-130.

Palm SL, Furcht LT (1983) Production of laminin and fibronectin by Schwannoma cells: cell-protein interactions in vitro and production localization in peripheral nerve in vivo. J Cell Biol 96:1218-1226.

Placzek M, Tessier LM, Jessell T, Dodd J (1990) Orientation of commissural axons in vitro in response to a floor plate-derived chemoattractant. Development 110:19-30.

Raper JA, Bastiani M, Goodman CS (1983) Pathfinding by neuronal growth cones in grasshopper embryos. I. Divergent choices made by the growth cones of sibling neurons. J Neurosci 3:20-30.

Reichardt LF (1992) Adhesive interactions that regulate neuronal behavior. In: Sensory neurons: diversity, development, and plasticity (Scott SA, ed), pp 215-241. New York: Oxford UP.

Reichardt LF, Tomaselli KJ (1991) Extracellular matrix molecules and their receptors: functions in neural development. Annu Rev Neurosci 14:531-570.

Riggott MJ, Moody SA (1987) Distribution of laminin and fibronectin along peripheral trigeminal axon pathways in the developing chick. J Comp Neurol 258:580-596.

Rogers SL, Letourneau PC, Palm SL, McCarthy J, Furcht LT (1983) Neurite extension by peripheral and central nervous system neurons in response to substratum-bound fibronectin and laminin. Dev Biol 98:212-220.
Rogers SL, Edson KJ, Letourneau PC, McLoon SC (1986) Distribution of laminin in the developing peripheral nervous system of the chick. Development 113:429-435.

Rutishauser U, Grumet M, Edelman GM (1983) Neural cell adhesion molecule mediates initial interactions between spinal cord neurons and muscle cells in culture. J Cell Biol 97:145-152.

Sabry JH, O'Connor TP, Evans L, Toroian RA, Kirschner M, Bentley D (1991) Microtubule behavior during guidance of pioneer neuron growth cones in situ. J Cell Biol 115:381-395.

Sanes JR (1989) Extracellular matrix molecules that influence neural development. Annu Rev Neurosci 12:491-516.

Schuch U, Lohse MJ, Schachner M (1989) Neural cell adhesion molecules influence second messenger systems. Neuron 3:13-20.

Schwartz. MA, Both G, Lechene C (1989) Effect of cell spreading on cytoplasmic $\mathrm{pH}$ in normal and transformed fibroblasts. Proc Natl Acad Sci USA 86:4525-4529.

Schwartz MA, Ingber DE, Lawrence M, Springer TA, Lechenc C (1991) Multiple integrins share the ability to induce elevation of intracellular pH. Exp Cell Res 195:533-535.

Schweighoffer T, Shaw S (1992) Adhesion cascades: diversity through combinatorial strategies. Curr Opin Cell Biol 4:824-829.

Scott SA (1988) Skin sensory innervation patterns in embryonic chick hindlimbs deprived of motorneurons. Dev Biol 126:362-374.

Snow DM, Letourneau PC (1992) Neurite outgrowth on a step gradient of chondroitin sulfate proteoglycan (CS-PG). J Neurobiol 23:322336.

Snow DM, Steindler DA, Silver J (1990a) Molecular and cellular characterization of the glial roof plate of the spinal cord and optic tectum: a possible role for a proteoglycan in the development of an axon barrier. Dev Biol 138:359-376.

Snow DM, Lemmon V, Carrino DA, Caplan AI, Silver J (1990b) Sulfated proteoglycans in astroglial barriers inhibit neurite outgrowth in vitro. Exp Neurol 109:111-130.

Sretavan DW, Reichardt LF (1993) Time-lapse video analysis of retinal ganglion cell axon pathfinding at the mammalian optic chiasm: growth cone guidance using intrinsic chiasm cues. Neuron 10:761777.

Stern CD, Keynes RJ (1987) Interactions between somite cells: the formation and maintenance of segment boundaries in the chick embryo. Development 99:261-272.

Tomaselli KJ, Doherty P, Emmett CJ, Damsky CH, Walsh FS, Reichardt LF (1993) Expression of $\beta 1$ integrins in sensory neurons of the dorsal root ganglion and their function in neurite outgrowth on two laminin isoforms. J Neurosci 13:4880-4888.

Tosncy KW, Landmcsscr LT (1985a) Development of the major pathways for neurite outgrowth in the chick hindlimb. Dev Biol 109:193214.

Tosney KW, Landmesser LT (1985b) Specificity of early motoneuron growth cone outgrowth in the chick embryo. J Neurosci 5:2336-2344.

Tosney K, Oakley R (1990) The perinotochordal mesenchyme acts as a barrier to axon advance in the chick embryo: implications for a general mechanism of axonal guidance. Exp Neurol 109:75-89.

Van den Pol AN, di Porizio U, Rutishauser U (1986) Growth cone localization of neural cell adhesion molecule on central nervous system neurons in vitro. J Cell Biol 102:2281-2294.

Walter J, Henke FS, Bonhoeffer F (1987) Avoidance of posterior tectal membranes by temporal retinal axons. Development 101:909-913.

Westerfield M (1987) Substrate interactions affecting motor growth conc guidance during development and regeneration. J Exp Biol 132 161-175. 